\title{
Shielding Design for the PGNAA Experimental Facility at Kartini Reactor
}

\author{
T. Sutondo ${ }^{*}$ and Syarip \\ Center for Accellerator Science and Technology, National Nuclear Energy Agency, \\ Jl. Babarsari, P.O. Box 6101 ykbb Yogyakarta 55281, Indonesia
}

\section{ARTICLE INFO}

\section{Article history:}

Received 28 June 2016

Received in revised form 19 April 2018

Accepted 19 April 2018

\section{Keywords:}

Shielding

Design

Radiation

PGNAA

Facility

Kartini reactor

\begin{abstract}
A B S T R A C T
Two steps of preliminary study had been conducted in conjunction with the design of a PGNAA experimental facility at Kartini reactor, i.e. beam characterization of the existing beam ports to select one going to be used and the collimator design at the selected beam port. This paper presents the results of the following study concerning with the radiation shielding design at the outer area, in front of the beam port exit, where the experiments will be conducted. MCNPX was used for the purpose of simulations, which included the design of neutron beam catcher and the outer shield. Based on the assumed source terms, the materials being used, and the geometrical arrangements, it is concluded that by using paraffin of $60 \mathrm{~cm}$ thickness for the beam catcher and $50 \mathrm{~cm}$ for the concrete of the outer shield would be sufficient to reduce the radiation dose below the maximum recommended limit.
\end{abstract}

() 2018 Atom Indonesia. All rights reserved

\section{INTRODUCTION}

Prompt gamma neutron activation analysis (PGNAA) is one of neutron activation analysis (NAA) techniques used in the elemental analyses. It works based on the gamma rays emitted promptly following the decay of the compound nucleus $(\mathrm{CN})$ formed in the excited state. This technique has some advantages compared with the traditional NAA, which works based on delayed gamma emitted by the activated nuclides, in terms that it can give result of examination more rapidly and without requiring irradiation process in reactor. These features have enabled to be used directly in the site of interest (in-situ) and in real time mode, such as those applied in several industries as in coal mining; cement industries, et cetera [1-3].

Kartini reactor is a pool type TRIGA Mark II reactor, operated with nominal power of $100 \mathrm{~kW}$, and has been operated since 1979 with the main function for education and research services [4]. It has several irradiation facilities, including 4 beam

\footnotetext{
${ }^{*}$ Corresponding author.

E-mail address:tegas@batan.go.id

DOI: https://doi.org/10.17146/aij.2018.904
}

ports that can be used for many different applications, as shown in Fig. 1.

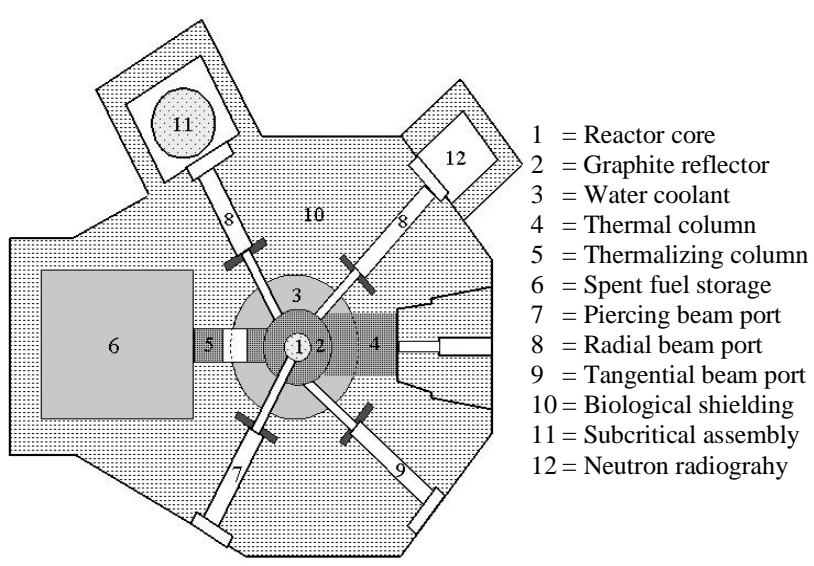

Fig. 1. Horizontal cut view of Kartini Reactor.

In conjunction with the revitalization program of Kartini reactor, there is interest to build a PGNAA experimental facility by utilizing one of the beam ports, which are still not utilized optimally, i.e. radial piercing, radial and tangential beam ports.

Two preliminary steps of activity have been carried out for this purpose, started with the characterization of the existing beam port to select 
one, which is considered to be the most suitable [5]. Based on the result obtained, it was then decided to use the tangential beam port for this purpose. The next step of work is to model the collimator at the tangential beam port intended to get mostly thermal neutron beam that will be used in the elemental analysis [6].

This paper presents the succeeding step of work concerning the design of shielding system at the outer area in front of the beam port that will be used for PGNAA experiment. It includes the design neutron beam catcher and the outer radiation shield. The beam catcher is intended to capture the neutron beam steaming out from the collimator exit and passing through the experimental sample, whilst the outer shield is intended to shield mostly the gamma rays originating both from the beam port's exit and those produced as secondary particles. Figure 2 depicts the layout of the shielding system of radiation coming from the beam port's exit. The effective thickness of the materials needed for both the beam catcher (a) and the outer shield (b) would depend on several factors, such as the source strength of the beam source, kinds of material to be used, and distance to the source. In this simulation the distance from the source to the beam catcher's gate was taken as $30 \mathrm{~cm}$ with the diameter of the beam catcher's gate (c) of $30 \mathrm{~cm}$.

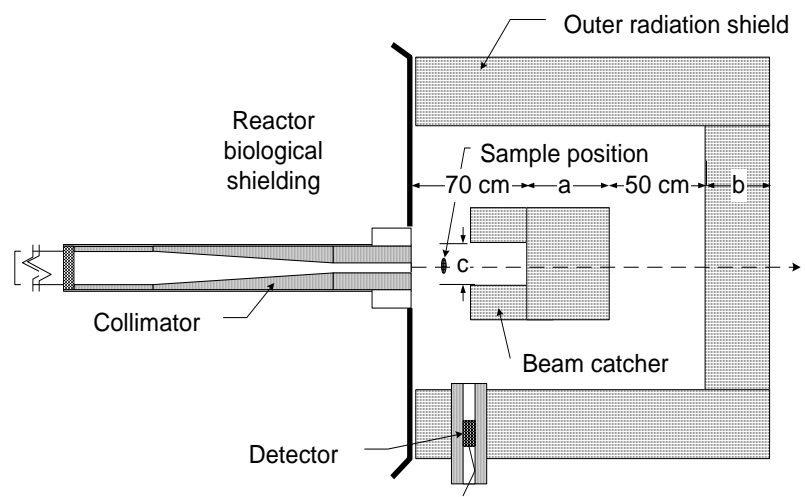

Fig. 2. Collimator, sample position and shielding system.

\section{METHODOLOGY}

\section{Source terms}

If the beam is well collimated, it is expected to contain mostly neutrons with a specific characteristic, which will be more easily to handle. However it could be different in reality, due to both the engineering and the computational factors. Therefore, for the purpose of improving the safety margin, the source terms for this design was to use the beam characteristics of tangential beam port's exit for the condition without the presence of collimator when the reactor was operated at $100 \mathrm{~kW}$. Thus, it contains both neutrons and photons for the whole energy ranges, as obtained in the previous calculation [5,6]. A $10 \%$ of correction factor was then added to the calculated values to include the maximum tolerance of reactor power calibration factor. Table 1 presents the characteristics of the beam source, which was used as the source terms in this calculation. Further, the beam was assumed to have mono direction.

Table 1. Characteristics of the source terms.

\begin{tabular}{ccc}
\hline Range of Energy & $\begin{array}{c}\text { Neutron flux } \\
\left(\mathrm{n} \mathrm{cm}^{-2} \mathrm{~s}^{-1}\right)\end{array}$ & $\begin{array}{c}\text { Photon flux } \\
\left(\mathrm{n} \mathrm{cm}^{-2} \mathrm{~s}^{-1}\right)\end{array}$ \\
\hline $\mathrm{E} \leq 0.5 \mathrm{eV}$ & $1.6801 \times 10^{8}$ & - \\
$0.5 \mathrm{eV}<\mathrm{E}<0.1 \mathrm{MeV}$ & $1.4875 \times 10^{8}$ & $2.4100 \times 10^{7}$ \\
$\mathrm{E}>0.1 \mathrm{MeV}$ & $5.4437 \times 10^{7}$ & $1.8900 \times 10^{8}$ \\
\hline Total & $3.7120 \times 10^{8}$ & $2.1340 \times 10^{8}$ \\
\hline
\end{tabular}

\section{Materials}

Paraffin wax composed of carbon and hydrogen with general formula $\left(\mathrm{C}_{\mathrm{n}} \mathrm{H} 2_{\mathrm{n}}+2\right)$ [7] is good neutron moderator that can be effectively used to slowdown the fast neutrons. The outer shield was to use ordinary concrete, which is commonly used for radiation shielding design [8,9], especially for gamma rays. Table 2 presents the data of chemical compositions and the corresponding density of main components used in this calculation.

Table 2. Chemical composition and atom density for concrete and air [9] and physical properties of paraffin.

\begin{tabular}{cc}
\hline \multicolumn{2}{c}{$\begin{array}{c}\text { Ordinary Concrete }- \text { KENO standard mix } \\
\left(\text { density }=2.3 \mathrm{~g} / \mathrm{cm}^{3}\right)\end{array}$} \\
\hline Chemical element & Atom density (atoms/barn.cm) \\
\hline $\mathrm{H}$ & $1.3740 \times 10^{-2}$ \\
$\mathrm{O}$ & $4.6060 \times 10^{-2}$ \\
$\mathrm{Si}$ & $1.6620 \times 10^{-2}$ \\
$\mathrm{Al}$ & $1.7500 \times 10^{-3}$ \\
$\mathrm{Na}$ & $1.7500 \times 10^{-3}$ \\
$\mathrm{Ca}$ & $1.5200 \times 10^{-3}$ \\
$\mathrm{Fe}$ & $3.5000 \times 10^{-4}$ \\
\hline \multicolumn{2}{c}{$\mathrm{Air}$} \\
\hline $\mathrm{N}$ & $1.0868 \times 10^{-5}$ \\
\multicolumn{2}{c}{ Paraffin: density $=0.9300 \mathrm{~g} / \mathrm{cc}$} \\
\hline Weight fraction: $\mathrm{C}=0.8514 ; \mathrm{H}=0.1486$ \\
Melting Point: between about 46 and $68{ }^{\circ} \mathrm{C}$ \\
\hline
\end{tabular}

MCNPX [10] was used to evaluate the fluxes and the corresponding doses as a function of thickness of the material being investigated. In this case, point detector tally (F5) has been used at several points of interest along the beam axis, and 
some variance reduction techniques were applied in this simulation. The standard dose function as prescribed by NCRP-38 1971; ANSI/ANS-6.1.11977 was used for converting the flux to radiation dose rate.

\section{RESULTS AND DISCUSSION}

Figure 3 shows the MCNPX geometrical representation of the beam catcher model, indicating vertical and horizontal cut view. In this case, the distance from the source to the beam catcher's gate and to the paraffin block was $30 \mathrm{~cm}$ and $70 \mathrm{~cm}$, respectively. The paraffin block was divided into several identical segments, each of which has $5 \mathrm{~cm}$ thickness, and aluminum (Al) of $0.5 \mathrm{~cm}$ thickness was used as casing for the paraffin.

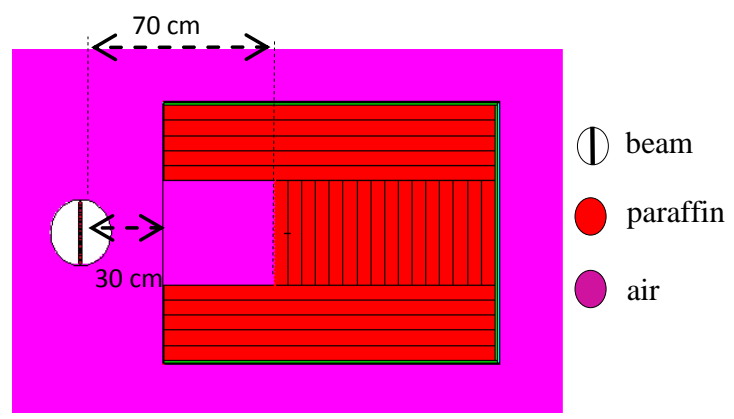

Fig. 3. MCNPX geometrical model of the beam catcher.

As the beam entering the beam catcher's gate, it will undergo collision process within the paraffin block. Figure 4 shows the collision density distributions of the neutrons in the beam catcher indicating that most collision reactions occur in the center area of the paraffin block. At the depth of around $60 \mathrm{~cm}$, the neutron intensity has been significantly reduced.

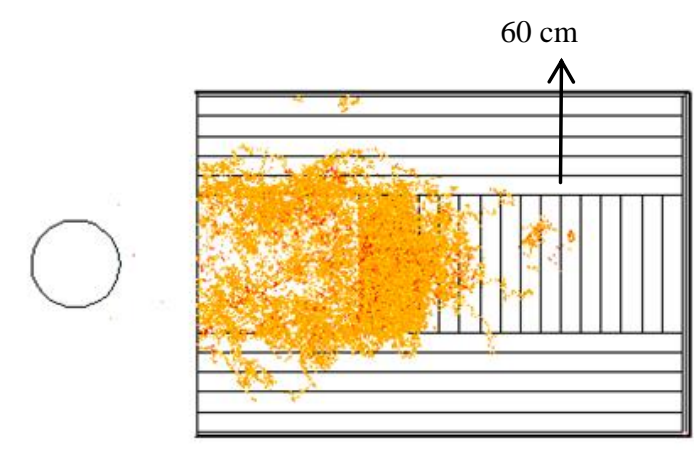

Fig. 4. Neutron collision density distributions in the beam catcher.

Figure 5 presents the neutron flux characteristics for paraffin thickness of $0,30,50$, and $70 \mathrm{~cm}$, respectively, which corresponds to the positions from the source of $40,70,90$, and $110 \mathrm{~cm}$ respectively, with relative error of $4 \%$. The result shows that, at $70 \mathrm{~cm}$ of thickness, the intensity has been significantly reduced. However, to improve the safety, the paraffin thickness can be extended as necessary.

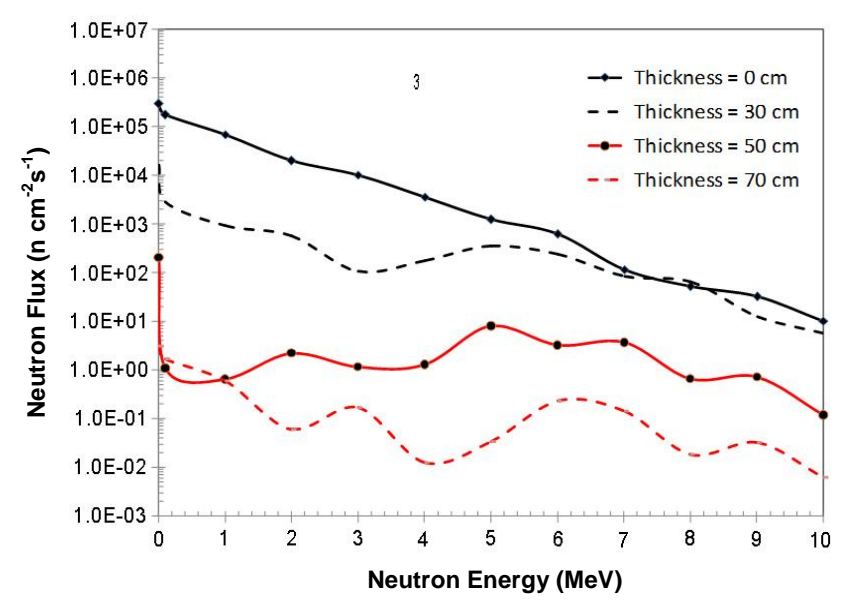

Fig. 5. Neutron characteristics as a function of paraffin thickness.

Figure 6 presents the corresponding dose rates as a function of paraffin thickness, ranging from 0 to $80 \mathrm{~cm}$ (corresponding to the distance from the source of 40 to $120 \mathrm{~cm}$ ). The result shows that at $60 \mathrm{~cm}$ of thickness the dose rate has significantly reduced, below the recommended maximum limit of $20 \mu \mathrm{Sv} / \mathrm{h}$ [11], and at $80 \mathrm{~cm}$ of thickness it becomes around $0.5 \mu \mathrm{Sv} / \mathrm{h}$.

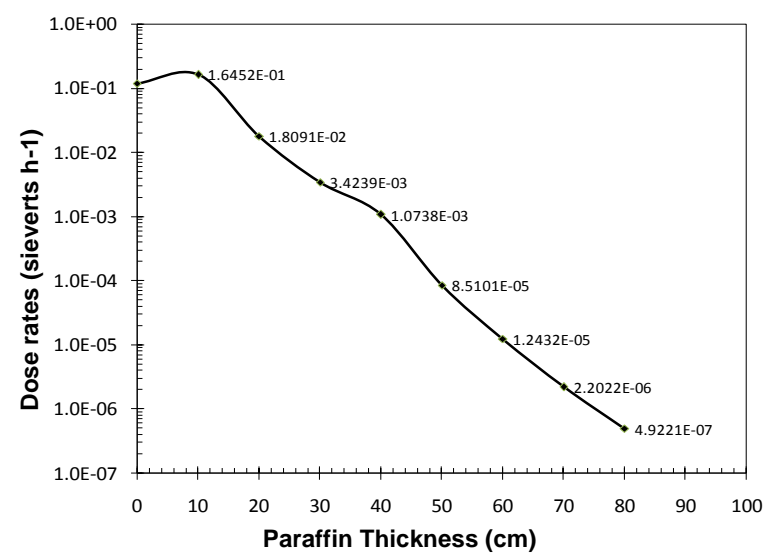

Fig. 6. Neutron dose rates as a function of the paraffin thickness.

\section{Outer shield}

Figure 7 depicts the MCNPX geometrical model of the shielding system, showing the beam source, beam catcher and the outer shield. In this simulation, the concrete block was divided into several layers, each of which has $10 \mathrm{~cm}$ thickness. The distance between the outer shield and the beam 
source was set forth $200 \mathrm{~cm}$ and the gap between beam catcher and the outer shield was $50 \mathrm{~cm}$. The simulation had been conducted for two cases, i.e. the radiation dose for the case with and without the presence of beam catcher.

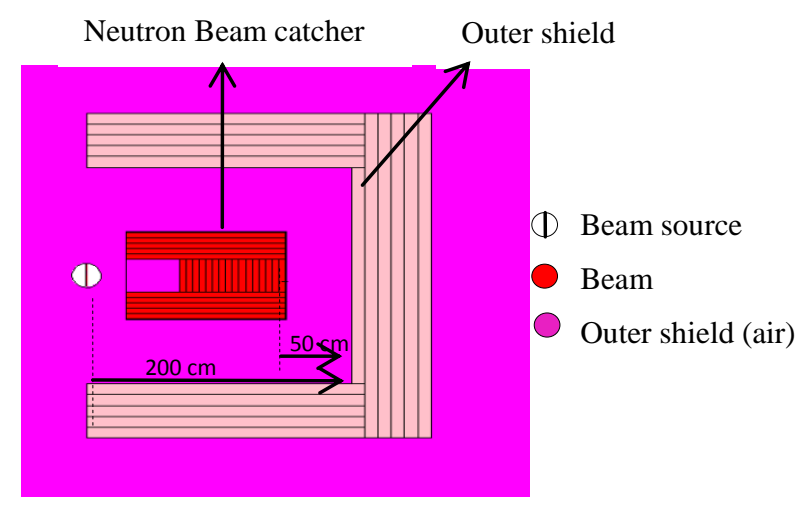

Fig. 7. MCNPX geometrical model of the shielding system.

Figure 8 presents the results of simulation, for the conditions with and without the presence of beam catcher. In the case without the presence of beam catcher, the intensity of both neutrons and gamma rays from the source will not be significantly during the passage to the outer shield. As the result, more gamma rays will be produced in the concrete as the result of neutron interaction with the concrete material. The result indicates that the neutron and the gamma radiation at the outer surface (60 $\mathrm{cm}$ of thickness) is still very significant with dose rate of around 0.42 and $0.11 \mu \mathrm{Sv} / \mathrm{h}$, respectively or with the total $0.53 \mu \mathrm{Sv} / \mathrm{h}$. This value is still far beyond the maximum recommended limit of $20 \mu \mathrm{Sv} / \mathrm{h}$ [11].

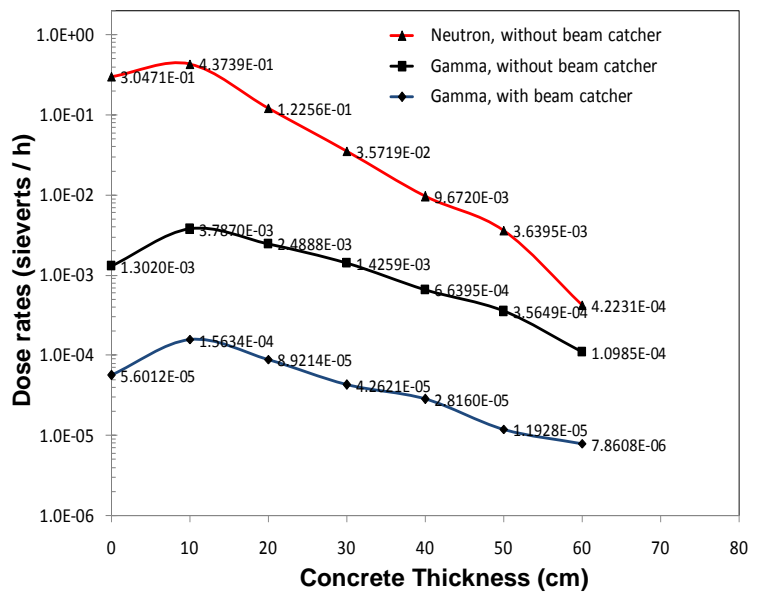

Fig. 8. Radiation dose rates as a function of concrete thickness of the outer shield.

If the beam catcher was retained in the place, most neutrons would be well absorbed in the beam catcher, and the gamma rays originating from the beam port and those produced as secondary particle would also undergo attenuation in it. As the result, the radiation dose at the outer shield had been significantly reduced, to be around $7.9 \mu \mathrm{Sv} / \mathrm{h}$, where the neutron contribution became extremely low, and was well negligible.

\section{CONCLUSION}

A series of MCNPX calculations had been conducted in conjunction with designing the shielding system for the proposed PGNAA experimental facility at Kartini reactor. The calculation included the design of neutron beam catcher and the outer shield. Based on the assumed source terms, and the geometrical arrangements, a minimum paraffin thickness of $60 \mathrm{~cm}$ of beam catcher would be sufficient to reduce the neutron's radiation dose below the maximum recommended limit. For the outer shield, using ordinary concrete, if the beam catcher was removed, the radiation dose rate at the outer surface of $60 \mathrm{~cm}$ thickness was still very high, beyond the permissible limit recommended. In this case, the contribution of neutrons and gamma rays produced as secondary particle was very significant. The presence of beam catcher can significantly reduce the contribution of neutrons and secondary particles to the radiation dose, and as the result the dose rates meets the recommended limit. For the condition where the beam source is well collimated, where the beam source contains only thermal neutron, this result will be much more conservative.

\section{ACKNOWLEDGMENT}

This work was funded by annual budget (DIPA) allocated by the Government of Indonesia to BATAN for the year 2016, in conjunction with the project of "Development of Nuclear Analysis Techniques using Research Reactor and Neutron Generator to Support Mapping of Air Pollutant Distributions".

\section{REFERENCES}

1. T.Q. Qasim, T. Al-Etaiwi and M. Al-Khasheb, Analysis and Developments of PGNAA Installation at Al-Rashadiya Lafarge Cement Plant in Jordan, Proceedings of the 2011 International Conference on Industrial Engineering and Operations Management, (2011) 1219.

2. D. Leetham, PGNAA Improves Process and Quality Control in Cement Production, Accelerating Science (2014) 1. 
3. A.A. Naqvi, M.A. Garwan, M.M. Mohiuddin et al., J. Nucl. Sci. Technol. 7 (2009) 737. http://dx.doi.org/10.1080/18811248.2007.9711 580

4. Anonymous, Kartini Reactor, http://www.batan. go.id/index.php/en/deputy-en/fasilitas-nuklir/ 143-kartini/1576-kartini-reactor-yogyakarta. Retrieved in December (2017)

5. T. Sutondo and Syarip, GANENDRA Journal of Nuclear Science and Technology 17 (2014) 83. (in Indonesian)

6. T. Sutondo, GANENDRA Journal of Nuclear Science and Technology 18 (2015) 107. (in Indonesian).

7. Anonymous, Paraffin Wax. https://en.wikipedia.org/wiki/Paraffin_wax.
Retrived in May (2016).

8. S. Orak and D.Y. Baysoy, Academic Platform Journal of Engineering and Science I-I (2013) 15. http://dx.doi.org/10.5505/apjes.2013.99609

9. H.M. Dalle and D.D.M. Campolina, Shielding Simulation of the CDTN Cyclotron Bunker Using MCNP, International Nuclear Atlantic Conference - INAC (2011) 10.

10. D.B. Pelowitz, MCNPX ${ }^{\mathrm{TM}}$ User's Manual, Version 2.6.0, LA-CP-07-1473 (2008) 551.

11. Anonymous, Radiation Safety Act: Dose Limits and Maximum Permissible Exposure Levels Fact Sheet, Government of Western Australia Radiological Council, Rev. 2.1 (2012) 1. 